\title{
Reducing Voluntary Turnover through Career Development: Strategic HRD Research Proposal
}

\author{
Tim McCafferty ${ }^{1}$ and Joseph Hamilton ${ }^{2}$ \\ 1Liberty University School of Business Doctoral Studies, Lynchburg, Virginia, United States \\ 2 College of Doctoral Studies, Franklin University, Columbus, Ohio, United States \\ *Correspondence: Tim McCafferty, tmccafferty@liberty.edu
}

\begin{abstract}
Voluntary employee turnover in the United States continues to spiral out of control and is expected to steadily increase in the coming years. Annual cost to American businesses exceeded $\$ 630$ billion and is expected to exceed $\$ 700$ billion within the next 24 months. The reasons for the sharp increase in voluntary turnover are not generational by nature as employees of all generations seek a connection with their employer and the ability to share in the firm's growth. The reasons expressed by employers and employees include lack of training, weak relationships with managers and a general disconnect from company strategy. The primary reason given in recent years is lack of career development. Scheduled, agenda-driven discussions between senior leadership and the employee is needed to focus on employee skills, capacity for learning and enterprise goals has shown promise in reducing voluntary turnover, increasing employee engagement, and increasing talent depth in medium and large businesses. Career planning and development is not necessarily transactional as it includes specific training for a specific purpose to fit the firm's strategic objectives. This approach can be used for lateral and vertical movement within the company. This proposal seeks to bridge the gap between existing literatures, current human capital management practices and move the discussion to a level that benefits employees and employers alike.
\end{abstract}

Keywords: Turnover, Career development, Strategic management, Human capital

\section{ARTICLE INFORMATION}

Author(s): Tim McCafferty, Joseph Hamilton

Received: 12 Nov, 2020; Accepted: 26 Nov, 2020; Published: 30 Dec, 2020 e-ISSN: 2347-4696;

Paper Id: BMN-IJBMR-2020-17;

Citation: doi.org/10.37391/IJBMR.080409

Webpage-link: https://ijbmr.forexjournal.co.in/archive/volume-8/ijbmr-080409.html

\section{BACKGROUND}

Voluntary turnover of all generations currently exceeds 20 percent annually. This has remained flat throughout 2020, despite temporary employment status changes caused by COVID-19 [1]. A study conducted by the Work Institute yielded data indicating turnover costs American businesses over $\$ 630$ billion per year and is expected to exceed $\$ 700$ billion by 2022, increasing each year thereafter [2]. This figure excludes indirect costs such as the cost of training new-hires, customer relationships, intellectual property, decreased productivity, and overall employee morale. It is far less expensive for organizations to train and hire from within than it is to seek external candidates [3]. Lack of career planning, weak communication with supervisors and lack of training opportunities are three of the top five reasons employees voluntarily leave their employer [4]. This is supported by research by the Work Institute's 2020 retention report. The Number One reason people voluntarily quit their jobs is lack of career development [2]. This proposal creates a path to bridge the communication gap between executive leaders and followers, thereby improving the working relationship. Additionally, the primary purpose of this proposal provides the justification for regularly scheduled career planning discussions and following through with employee training, thereby mitigating the likelihood of voluntary turnover within the organization.

A significant amount of scholarly research has been done about how managers and leaders should act when managing employees. There is a gap between how organizations should engage employees and the level of engagement that is delivered. This lack of follow-through is cited as one of the main reasons for voluntary turnover [4]. Part of the engagement is personal growth and development and development opportunities within the organization. This is where the gap is at its widest point. More research is needed in the member-leader exchange, specifically when it applies to career development and planning. Current literature addresses primarily day-to-day interactions, coaching and member improvement. Little research exists about specific steps to follow to match employee desires and skills to current and future enterprise needs. This must be done at the executive level, rather than through the direct manager. Additionally, once various career options are identified and agreement is reached, the executive must proactively schedule requisite training to facilitate progression in the employee's career path. Presently, research indicates this is done with the primary supervisor. As a result, voluntary employee turnover persists specifically because of a lack of career training opportunities [4]. Employee development discussions should be held at the executive level, not at the line-supervisor level. The discussions should be scheduled on a periodic basis - every four to six months. This ensures training is ongoing and allows the executive to modify the training schedule as needed to fit within the firm's strategic objectives.

\section{LITERATURE REVIEW}

Current literature reinforces thorough and ongoing training and its impact on retention. Employee training benefits the 
employee and the employer in the near- and long-term perspective [5]. Training must be a consideration in the strategic planning and budgeting process of the organization and that is accomplished with buy-in from senior leadership [5]. Continuous training of employees reduces overhead expenses and is positively correlated with higher employee retention [6]. A commitment to training also sends a strong message to employees that "the organization really has the employees' best interest at heart" [7]. This message will have as much if not more impact on small and medium sized companies where the training budget is often smaller than that of larger organizations [8].

Maier [9] discussed the positive impact of career ladders on employee development and retention. While the context is in Certified Nursing Assistant (CNA), the concept is easily transferrable to any corporate setting. In Maier's study, career ladders consisted of three levels of training. While successful completion of the progressive education does not guarantee advancement in a specific organization, it does increase retention and make the employee more marketable [9]. The career ladder concept requires the employee to be at a certain level for a minimum defined period of time - typically six months to one year. After satisfying the requisite timeline, the employee is eligible for skill testing. The employee then advances to the next level and follows the same protocol. In nursing, the CNA certification has three levels, each with specified hours of training and testing [9].

A separate study found a positive correlation between career ladders in nursing and employee retention [10]. The study also found increased competency with career ladders which led to patient safety and employee engagement [10]. This study illustrates the result in decentralization, autonomy and poorly communicated strategies. Subjects of the study were nurses progressing through their respective careers. The subjects were satisfied with the $\neg$ concept of continuing education but were dissatisfied with the process. The government of Indonesia failed to communicate the positive aspects and the need for career ladder training. One of the most significant aspects of this study was competency assessments were conducted only at the end of a particular stage in the training, rather than on an ongoing basis [10]. There may have been other factors involved in the dissatisfaction score such as irregular shifts, working hours, etc., but the primary driver was poorly communicated goals of the continuing education. Communicating with clarity and regularity is critical for manager-employee relations [5].

One study recognized some organizations offer little, if any vertical job mobility. In that situation, lateral mobility is a viable option [11]. Internal movement within an organization is still classified as career growth and is often accompanied by increases in pay [11]. The "monkey bar" model shows positive correlation between development and slight positive impact on employee retention. Turnover decreased in the first five years of the study [11]. Companies would be wise to consider this strategy if applicable. Lateral job movement is a sound strategic strategy as it utilizes employees' skills where they are best suited for the employee and organization [12].

One especially important variable in turnover is the employee's attitude toward their employer. Organizational career growth is positively correlated with organizational commitment [13]. Simply put, employees are more committed to their company if they have growth opportunities within their organization. Successful interventions on turnover include vertical and lateral job transitions; continuous training in job and non-job skill development and improved interpersonal relationships with team members and managers [13]. Weng \& McElroy's study also reached the same conclusion as Mello [5] and Blocher [12] that turnover can be reduced through increased engagement by supervisors and providing a clearly articulated career path [13]. One area that received little attention in Weng \& McElroy's [13] study is the importance of training as a way to mitigate voluntary turnover. This is consistent with an earlier study wherein it was concluded giving employees the opportunity for lateral movement with the organization had a positive influence on worker attitudes and engagement [14].

Training opportunities affect employee perception about their employer [15]. It is incumbent upon leadership to create a positive perception by offering a multitude of training opportunities for all employees. It is equally important for employees to see training opportunities outside of the normal scope of work. Employee perception about training is positively correlated with their intention to leave the employer in favor of another company that does offer significant training opportunities [15]. One method employers can improve employee perception is by offering a plethora of online courses. This concept of "Massive open online courses" (MOOC) was the basis of a 2017 study wherein it was concluded employees favored the online courses, yet most American employers opted to not participate in limited course offerings that were directly relevant to the organization or its industry. The companies that do offer online coursework often include job-specific training but also offer topics of varied interest, including higher education courses. Interestingly, the companies that invested in the infrastructure necessary to support MOOC experienced less-than-average employee turnover [16].

Brown \& Reich [17] conducted a study that compared the career ladder system in Japanese companies versus American companies. The premise of the system acknowledged the cultural differences between the two countries, particularly the traditional lifelong employment of Japanese workers and the more transitory nature of American workers. The key takeaways from the study are Japanese worker training and development is more structured and regulated whereas American on-the-job training is heavily weighted upon hire and little formal training thereafter [17]. Mello [5] describes this type of practice as not conducive for the individual worker or the organizational strategy. 
The difference in training levels between managers and nonexempt employees is stark [17] Managers receive training upon hire and semi-consistently throughout their tenure while non-exempt workers usually receive specific job-related training upon hire and little thereafter [17]. The study continued by observing nearly 80 percent of the surveyed companies offered no informal training as the on-the-job training was "sufficient" [17]. It seems little has changed in the last 23 years. By contrast, Japanese firms continuously train employees throughout their careers. The authors posit this also is correlated with lower turnover than American counterparts [17]. An interesting observation referenced in the study is Japanese workers traditionally rely heavily upon networking and have for decades, while American workers are just beginning to learn the art of networking for career advancement [17]. This is consistent with assertions made in an article that appeared in International Economic Review [18]. In the article, the authors observe American workers are seeking better development opportunities through networking much more so than in prior times.

Mello [5] stresses the need for training employees. There are numerous studies that provide a direct correlation between employee training and productivity, engagement and reduced turnover. For reasons known only to them, it seems many American companies have not implemented solid HRD practices of continuous training opportunities to workers. Bukach, Ejaz, Dawson and Gitter [19] conducted a study of mental health workers in Ohio and discovered 61 percent of employees that voluntarily quit their jobs to pursue training in school or other sources [19]. This offers further evidence of a direct relationship between turnover and training. Bukach, et al. [19] used 2011 data. A newer study using newer data should be conducted to learn if the outcome is altered by time.

Benko and Weisenberg [20] presented an interesting observation of the need for a mixed-model organization. This study took attributes from traditional hierarchy-structured model and attributes from a flattened "corporate lattice" and found commonality in the middle. The traditional corporate ladder offers one way up, the employee either moves up or stops moving, provides a work-over-life approach, is patterned for the traditional family structure and assumes employee needs do not change over time. Conversely, the corporate lattice approach is geared more for workplace evolution, multiple advancement paths, agile enough to change pace as needed and achieves the coveted work-life balance required by younger generations. The key is the intersection between the traditional corporate structure and the progressive structure. Upward mobility and integrated talent management systems bridges the two models [20]. The study found the lattice model works for all generations, not just Millennials.

Benko and Weisenberg [20] also formulated a new model that is gaining traction with American companies. The Mass Career Customization (MCC) is a highly flexible model that addresses worker's needs while achieving organizational strategic goals. The MCC has "four core dimensions of a career: pace, workload, location/schedule and role" [20]. Pace is a function of time and refers to how rapidly an employee is slated to assume increased responsibility. Workload refers to the quantity of work the employee is able to complete accurately. Location/schedule refers to when and where the work is completed. Role refers to current category of the employee within the organization [20]. This model is appealing to all four generations currently in the workforce [20].

An interesting article about the importance of employee training and the costliness of neglect appeared on Forbes.com. Perhaps the most neglected area of management is development planning [21]. Some of the reasons for neglect presented in the article include the tendency for immediate focus - the "here and now," corporate bureaucracy focuses more on planning than implementation and no time for development [21]. Corporate development is a requisite for longevity and employee retention. As Lipman [21] wrote, people do care about their organization when managers take a genuine interest in the employee's future. He continued, development builds loyalty and that leads to productivity. Lastly, Lipman [21] wrote good employees want advancement and appreciate a supportive environment. Lipman's article is one of many supportive of employee training. One important aspect omitted from Lipan's article is how development can address and correct weaknesses in workers' skills [22]. Lipman's observations and the article from 2020projectmanagement.com are consistent with this literature review. The theme is common: employee training improves engagement and retention while increasing productivity. Employees of all generations share the expectation of training, growth and development in the workplace [23]. It is incumbent upon the HRD professional to lead the charge for organizational change to develop a culture of learning [5]. The leader should be a good teacher to help develop followers.

Taking an interest in employees' growth and development is servant leadership at its core. Servant leadership can be defined as a natural feeling that one wants to serve - to serve first. Individuals must make a conscious choice to aspire to lead. The primary difference is the care taken by the servant to ensure other people's needs are being serviced [24]. Servant leadership works when the leader puts employees' needs ahead of his or her needs and works when the model is consistently applied. Servant leadership is a process as well as a mindset. For a leader to be a successful servant leader, the leader must first understand each member of the team and put the member's needs ahead of the leader's needs. When the leader demonstrates a genuine interest in the worker, the worker develops and productivity increases [24]. As the worker continues to develop, the worker becomes a better contributor at work, at home and in society. The organization benefits as much as the worker in that strategic goals can be met because each team member feels more valued and becomes more productive.

Workers of all generations expect their employers to help them develop useful and contributory skills for the betterment of the organization [23]. Managers expect new hires to possess 
certain basic skills; thus, managers and new hires are parties to a "psychological contract". This is where both parties have expectations of each other. Relations break down when one party fails to live up to the terms of a psychological contract.

\subsection{Gap in the Literature}

For the most part, existing literature emphasizes the need for and benefit from career development. With the notable exception of Maier's [9] study about scheduled training from progressive development within the CNA field, little research exists concerning the member-executive relationship regarding scheduled career planning and development. Much research has been done regarding benefits in addition to monetary compensation. More research is needed in this area to identify companies that practice scheduled discussions and what impact, if any, this process has had on the firm's voluntary turnover.

\section{RESEARCH METHODOLOGY}

Qualitative research will be used throughout this study with a narrative and phenomenology focus. Open-ended and exploratory questions will be asked of study participants. Responses are expected to have multiple answers and the data may be difficult to verify due to the individualized focus of the study [25]. Though the nature of the study is highly subjective, the data should be able to reach a consistent conclusion fully and accurately. This research will be done in an honest and ethical manner and a review panel will review methodology, coding and data interpretation to mitigate researcher bias.

\subsection{Problem Statement}

The general problem to be addressed is a high voluntary turnover rate in the American workforce. The United States Bureau of Labor Statistics reveals the annual turnover rate from 2014 to 2019 averaged 23.46 percent, increasing in each year of the five-year period [1]. The specific problem to be addressed is how career development discussions and ongoing training affect a person's choice to voluntarily quit their job.

\subsection{Purpose Statement}

The purpose of this qualitative research study is to determine how employees' attitudes and tenure are affected by the training opportunities within an organization and the manager's commitment to the employee's success. This study examines the relationship between employee and employer expectations and behaviors and may yield ways employers could modify current approaches to employee growth and development. The working theory of this proposal is dedicated training reduces voluntary turnover.

\subsection{Rationale}

This research method was chosen as it allows the participants to provide detailed answers about their thought process at work and ultimately the root cause(s) and meanings behind the reasons people quit their job. The need for career development is expected by all generations in the workforce [4]. Two employee expectations to be examined in this research are identified as career development and open communication with an employee's supervisor [4]. Career development and management behavior appeared as the first and third reasons people leave an organization, respectively [23]. Turnover trends will also need to be monitored going forward statistical data will likely change. Management behavior is defined as a "positive and productive relationship" [23]. The study conducted by the SHRM supports the Sears' research. "A career development path provides employees with an ongoing mechanism to enhance their skills and knowledge that can lead to mastery of their current jobs, promotions and transfers to new or different positions" [26].

\subsection{Nature of the Study}

The following open-ended and exploratory research questions are consistent with qualitative research. These questions are suitable for narrative research and phenomenology and multiple answers are expected [25]. The data may be difficult to verify because of the individualized nature of the study. To mitigate this, respondents will be asked to review the transcript of their individual interview(s) for accuracy and clarification [25].

\subsection{Research Questions}

All survey-related questions will be linked to these research questions.

1. How does the lack of career development affect employee turnover?

2. How does ineffective communication with a manager affect employee turnover?

3. How does a having structured and scheduled training impact employee turnover?

\subsection{Research Design}

The study will be conducted by surveying employees who are currently employed with firms listed in Gallup's article entitled, "40 Top Workplaces You'll Want to get to Know." This 2019 article lists a ranking of firms with high employee engagement and low voluntary turnover. Another source is employees who work or have worked with firms listed on Payscale.com's annual ranking of the most and least loyal employees. While both lists are highly unscientific, they should provide a good cross section of satisfied and dissatisfied employees. Interviews will be thematically coded to reflect worker sentiment. Each interviewee will be assigned a number as an identifier, starting with 001. Each transcription of interviews will be shared with the interviewee for accuracy. This is predicated upon having the interviewee's contact information. Data will be collected at the time of the interview and sorted by theme after each interview has been completed. Coding will be logged on a Microsoft Excel spreadsheet. Once the data has been checked for accuracy, the coded responses will be entered into MaxQDA software for analysis.

Open-ended interview questions:

1. Please describe your employer's (or former) career development program.

2. Please describe the level of your training at your current job. 
3. What levels of interaction have you had with senior management or Human Resources about your training and development?

4. If you recently left an employer, please describe why you left. If currently employed, what is it about your company that keeps you working there?

5. If you recently left an employer, what would have made you remain with the employer?

Voluntary turnover can be traced to multiple reasons and the topic has been widely researched. This study will contribute to further research by limiting the focus to one specific cause and one possible secondary cause: the lack of training opportunities post-hire and the relationship with the manager. The basis of the study is to determine a causal relationship between training opportunities and employee tenure.

God provides specific instructions how people should interact with each other. Teaching and development are found in Job, "Teach me, and I will be silent; And show me how I have erred" [27]. It is incumbent on everyone in any leadership capacity to be engaged in the development of others.

\section{CONCLUSION}

Employee turnover in American companies averages over 20 percent per year and is expected to rise in the coming years. Some turnover has to do with the interpersonal relationships between the employee and the manager. Much of the turnover can be attributed to lack of training and development opportunities. Lack of training opportunities was cited as a primary reason people voluntarily quit their jobs. Workers of all generations expect initial training upon joining an organization. They also expect training throughout their employment. Numerous studies were presented all had a consistent theme: training increases employee engagement, increases productivity and reduces turnover. American companies would be wise to study Japanese companies to learn about the commitment to training during an employee's career. Japanese companies have a culture of training and development. This study will examine the specific reasons for voluntary turnover and seek to find the causal relationship between voluntary turnover and training opportunities.

When a leader truly commits to learning about his or her employee's needs, the leader can then be trusted to guide the employees through whatever training is deemed necessary to improve the employee. This is servant leadership, and it must be one of the leader's core beliefs. Training and development are part of God's plan and leaders are expected to help followers in their journey. There is evidence to support the theory training leads to development and increased productivity. The payoff for all stakeholders is huge. Employees win. Leaders win. The company wins. The downside risk is minimal compared to the upside potential, whether or not American employers implement ongoing training warrants further investigation. Voluntary turnover can be traced to multiple reasons and the topic has been widely researched. This study will contribute to further research by limiting the focus to one specific cause and one possible secondary cause: the lack of training opportunities post-hire and the relationship with the manager. The basis of the study is to determine a causal relationship between training opportunities and employee tenure.

\section{REFERENCES}

[1] U.S. Department of Labor, Bureau of Labor Statistics (2020) Table A: Annual quit rates by industry and region, not seasonally adjusted.

[2] Fox, C. (2020). Work Institute releases national employee retention report.

[3] Adams, S. (2012). Why promoting from within usually beats hiring from outside. Leadership.

[4] Moore, S., Grunberg, L., Krause, A. (2015). Generational differences in workplace expectations: A comparison of production and professional workers.

[5] Mello, J. (2019). Strategic human resource management (5th ed.). Boston, MA: Centage

[6] DiTieri, R. (2017, 10). Top reasons why you need to invest in employee training. Talent Management Excellence Essentials.

[7] Graduate training and employee retention: Some key HR practices. (2017). Human Resource Management International Digest, 25(6), 27-29).

[8] Beynon, M., Jones, P, Pickermell, D. \& Packham, G. (2015). Investigating the impact of training influence on employee retention in small and medium enterprises: A regression-type classification and ranking believe simplex analysis on sparse data. Expert Systems, 32(1), 141-154.

[9] Maier, G. (2002). Career Ladders: An important element in CNA retention. Geriatric Nursing, 23(4), 217-219.

[10] Hariyati, T., Sri, S., Igarashi, K., Fujinami, Y., Susilaningsih, F., \& Prayenti, S., M. Kes. (2017). Correlation between career ladder, continuing professional development and nurse satisfaction: A case study in Indonesia. International Journal of Caring Sciences, 10(3), 1490-1497.

[11] Dohmen, T., Kriechel, B., \& Pfann, G. (2004). Monkey bars and ladders: The importance of lateral and vertical job mobility in internal labor market careers. Journal of Population Economics, 17(2), 193-228.

[12] Blocher, E., Stout, D., Juras, P., \& Smith, S. (2019). Cost management: A strategic emphasis (8th ed.). Boston, Massachusetts: McGraw-Hill.

[13] Weng, Q. \& McElroy, J. (2012). Organizational career growth, affective occupational commitment and turnover intentions. Journal of Vocational Behavior, 80(3), 256-265.

[14] Kotorov, R. \& Hsu, E. (2002). A roadmap for creating efficient corporate internal labor markets. Career Development International, 7(1), 37-46.

[15] Ohunakin, F., Adeniji, A., Olunday, O. \& Osibajo, O. (2018). Perception of frontline employees towards career growth opportunities: Implications on turnover retention. Business: Theory and Practice, 19(1), 278-287.

[16] Egloffstein, M., \& Ifenthaler, D. (2017). Employee perspectives on MOOCs for workplace learning. TechTrends, 61(1), 65-70.

[17] Brown, C., \& Reich, M. (1997). Developing skills and pay through career ladders: Lessons from Japanese and U.S. companies. California Management Review, 39(2), 124-144. 
[18] Arbex, M., O'Dea, D. and Wiczer, D. (2019), Network search: Climbing the job ladder faster. International Economic Review, 60: 693-720.

[19] Bukach, A., Ejaz, F., Dawson, N., \& Gitter, R. (2017). Turnover among community mental health workers in Ohio. Administration and Policy in Mental Health and Mental Health Services Research, 44(1), 115-122.

[20] Benko, C. \& Weisenberg, A. (2007). Implementing a corporate career lattice: The mass career customization model. Strategy \& Leadership, 35(5), 29-36.

[21] Lipman, V. (January 29, 2013). Why employee development is important, neglected and can cost you talent.

[22] Business Insight, Ltd. (2017.). The importance of training and development in the workplace.

[23] Sears, L. (2017). 2017 retention report: trends, reasons \& recommendations.
[24] Northouse, P. (2016). Leadership theory and practice (7th ed.). Thousand Oaks: CA. Sage Publications, Inc.

[25] Robson, C. \& McCartan, K. (2016). Real world research (4th ed.). West Sussex, United Kingdom: Wiley.

[26] "Developing employee career paths and ladders." (n.d.). Society for Human Resource Management (SHRM).

[27] Job 6:24, NIV.

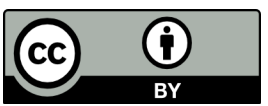

(C) 2020 by the authors. Submitted for possible open access publication under the terms and conditions of the Creative Commons Attribution (CC BY) license 